\title{
High-energy $\mu$-XRF-XAFS analysis of ion-adsorption-type rare earth deposit
}

MAKOTO NAGASAWA ${ }^{1 *}$, OHKI SEKIZAWA ${ }^{2}$, KIYOFUMI NITTA $^{2}$, YOSHIO TAKAHASHI

${ }^{1}$ The University of Tokyo

(*correspondence: m.nagasawa71358@eps.s.u-tokyo.ac.jp, ytakaha@eps.s.u-tokyo.ac.jp)

2 Japan Synchrotron Radiation Research Institute (sekizawa@spring8.or.jp,nittak@spring8.or.jp)

We performed $\mu$-XRF-XAFS analysis toward ionadsorption-type rare earth element (REE) ore sample in order to identify the host phase of REE and to clarify the adsorption characteristics using the synchrotron radiation Xray microbeam at BL37XU of SPring-8. We realized the high-energy X-ray microbeam (photon energy: $40 \mathrm{keV}$; beam size: smaller than $0.8 \mu \mathrm{m}$ (horizontal) $\times 0.4 \mu \mathrm{m}$ (vertical)) using a newly developed K-B mirror system, and performed XRF mapping and K-edge XAFS (HE- $\mu$-XRF-XAFS). Previous REE-XAFS analysis excited L3-edge of REE with a problem that L-lines of REE are interfered by K-lines of transition elements, when we analyze natural samples including various metal ions. However, the HE- $\mu$-XRF-XAFS is not subject to the interferences.

In addition, we quantitated REE concentration at local area to obtain REE pattern by the method without strong needs to correct the absorption effect, since absorption of Xray by the matrix material can be negligible for the thinsection analysis using hard X-ray above $30 \mathrm{keV}$. As a result, two types of REE enrichment were observed. One is the widely-distributed REE enrichment which indicates typical characteristics of ion-adsorption-type ore such as negative cerium anomaly, and the other is REE hot spot which indicates typical characteristics of igneous REE mineral with LREE-rich REE pattern.

This method, HE- $\mu$-XRF-XAFS, is superior to laserablation ICP-MS in terms of the spatial resolution and determination of REE speciation using EXAFS, which can be a very powerful method for the REE study for natural samples. 